\title{
Cost Deployment Tool for Technological Innovation of World Class Manufacturing
}

\author{
Luan Carlos Santos Silva, João Luiz Kovaleski, Silvia Gaia, Manon Garcia, \\ Pedro Paulo de Andrade Júnior \\ Department of Production Engineering and Technology Transfer Research Group, \\ Federal University of Technology-Paraná (UTFPR), Ponta Grossa, Brazil \\ Email: luancarlosmkt@gmail.com,kovaleski@utfpr.edu.br, gaia@utfpr.edu.br, \\ manongarcia@yahoo.com.br, pedropaulo@utfpr.edu.br
}

Received October 16, 2012; revised November 18, 2012; accepted December 2, 2012

\begin{abstract}
This article brings a discussion about using the Cost Deployment methodology for technological innovation in the World Class Manufacturing (WCM) systems at Fiat Group Automobiles Production System (FAPS). It aims to show how this tool acts in the technical pillars of the WCM, and its proper use as an alternative to innovate in production processes, achieving a drastic reduction in wastes and cost optimization during specific activities in production systems. The Cost Deployment builds a distinctive transversal method of WCM which helps to promote and provide extremely effectiveness in the activation of more specific methods that have been tried successfully in the Japanese manufacturing improvements. It also allows to link the operational performances, usually measured with indicators such as efficiency, providing number of defects, hours of desaturation. The used methodology was based on a literature review about the proposed topic. It ends up finding that the Cost Deployment tool is one of the most sophisticated technological innovations existing for the production systems of the World Class Manufacturing.
\end{abstract}

Keywords: Cost Deployment; Technological Innovation; World Class Manufacturing; Fiat Group Automobile Production Systems

\section{Introduction}

In the current scenario, the process of industrial system modernization is linked to the technological innovation and new technology of products, processes and services, demanding from companies a continuous seeking for innovation in their activities and production systems. Companies aim to increase optimization of costs, as well. In the role of these new parameters in the industrial sphere, many companies from various sectors have been involved in rethinking their old forms of production.

This paper was developed in the nucleus of Postgraduate in Management for Sustainability and Innovation at the State University of Santa Cruz (UESC), by the Research Group on Management Technology Transference of the Post-Graduation Program in Engineering of Production at the Federal University of TechnologyParaná (UTFPR). And it is under discussion here the use of the Cost Deployment Methodology as the new technological innovation of the World Class ManufacturingWCM, at Fiat Group Automobiles Production Systems (FAPS). Therefore, it aims to describe the tool Cost Deployment inside the technical pillars of the WCM and the appropriate use of this tool as an alternative to innovate in production processes, achieving a drastic reduction of wastes and costs. The optimization of specific activities in production systems enables an increasing on the identification of losses in the entire logistics chain. According to Yamashina [1], "The identification of losses depends on your eyes [...] people improve their eyes as they learn."

The Cost Deployment is a distinctive and transversal method of WCM which helps to promote and provide extremely effectiveness in the activation of more specific methods that have been successfully tried in the Japanese manufacturing improvements [2].

The used methodology is based on a literature review about some concepts on Technological Innovation, World Class Manufacturing, production systems at Fiat Group Automobiles Production System, and Cost Deployment. Considerations were discussed about the main relationships among the themes in order to explain its importance in the production chain.

The World Class Manufacturing is a set of concepts, principles and techniques for managing the operational processes of a company. The term World Class Manu- 
facturing effectively captures the essence of the fundamental changes taking place in world industries in the 1970s in a very wide set of elements that characterize the production: quality management, industrial relations, the training, support staff, sourcing, relationships with suppliers and customers, product design, organization of establishments, the scheduling, maintenance, production line, the accounting system, automation and others [3].

The WCM is based on models created by the activities of Japanese manufacturing after World War II and the results obtained by the Japanese approach in order to organize production. It adapts the ideas used by the Japanese in automobile and electronics sectors to achieve significant competitive advantages.

The WCM was first presented as an organic approach by Schonberger [4]. It shows a series of American companies which have adopted and implemented the Japanese approach to production, adapting it to the Western context. From the text of Schonberger [4] it is possible to identify that this adaptation has not occurred by pure imitation, but the adoption of the Japanese ways of producing in the West helped to publicize a very different approach. However, these changes generate a need for creating continuous technological innovations stimulated and generated by people in companies, aiming to manage and keep working in the current competitive environment.

\section{Technological Innovation}

In a highly competitive market, with production processes filled with organizational bottlenecks, the generation of innovations becomes critical in this process; organizations can continuously improve their processes through products and services. Innovation is an evolving set of new evolutionary functions that change the production methods, creating new ways of organizing work, and in producing new products, stimulating the opening of new markets by creating new uses and consumptions [5].

Following the same analysis Canon [5], relates that the concept of technological innovation can be understood as the expansion of production (more machines) and the increase of new products. In other words, it means that the company should think about producing products which have been produced by other manufacturers or competitors. In this same perspective, innovate is create and is also improving in products or processes that are working or can make a good profit. Innovate is to produce what the company did not deliver before. Innovation is expanding industrial sheds, is to install more machines, and is to install more modern machines let that to produce more quantity of products. Many times is to increase the productivity and optimize costs, mostly is to increase the production.

Therefore, technological innovation must be undermnstood as an activity that involves not only the industry in re- search and development in an organization, not even as an activity performed only by large companies. It must always be presented in all companies wishing to act in an innovative and competitive way in the market [6].

\subsection{WCM Concepts through Its Evolution}

There is no consistent definition of WCM, as many other new concepts related to management and supply chain. The term "World Class Manufacturing" was created by Hayes \& Wheelwright [7] and Schonberger [4], to describe the technological capabilities that had been developed by Japanese and German companies, as well as U.S. companies that had competed on equal terms with Japanese and German companies. The term WCM was used because these companies have achieved an outstanding performance in their global competition, resulting in the concept described as "World Class". However, the term became popular only after Schonberger [4] discussed the issue as: "[...] The term captures well the breadth and the essence of the fundamental changes taking place in industrial companies." WCM is a major philosophies focusing primarily on production, with a level of excellence throughout the logistics and productive cycles, in reference to the methodologies applied and the performances achieved by the best companies worldwide, mostly based on the concepts of Total Quality (TQC), Total Productive Maintenance (TPM), Total Industrial Engineering (TIE) and Just Time (JIT).

It is noteworthy that the critical factors of WCM success during the recent years have received widespread attention. It also became one of the driving forces for business success. Huczynski and Buchanan [8], EscrigTena [9], Flynn et al. [10], McAdam and Henderson [11], Oakland [12], Salaheldin and Eid [13], Sharma and Kodali [14], Sinclair and Zairi [15], Sohal and Terziovski [16] and Svensson and Klefsjo [17] conducted extensive studies to understand the factors that strengthen and enforce WCM application. These cited authors concluded that companies need to understand how to identify the critical factors which affect the implementation process by analyzing their tools in order to solve them effectively. This procedure ensures that benefits can be realized and established so faults can be drastically avoided. Therefore the need for a more systematic and deliberate study on the critical factors of success on implementing WCM is still considered fundamental.

Critical factors of success can be defined as areas where things should go well for the business to flourish, Butler and Fitzgerald [18], Digman [19], Eid et al. [20]. Oakland [21] highlights the importance of observing 
such critical areas in which the organization must have a greater attention to achieve the organization's mission, through examination and classification of impacts. In terms of WCM, they can be viewed as the activities and practices that should be addressed to ensure its successful implementation.

According to Sinclair and Zairi [15] the quality department plays a key role in implementing WCM, since proper training is provided to this department, EscrigTena [9], McAdam and Henderson [11]. However, the support of the senior management team is essential to integrate systems with the implementation plan for WCM, Avlonitis and Karayanni, [22], Mora-Monge et al. [23]. Bose [24] reinforces that programs of people awareness management are important for WCM implementation.

In the current literature, there is a considerable discussion about the importance of the human dimension in WCM implementation. It is taken as a facilitator of the process, not just an adjuvant, Flynn et al. [10]. Sureshchandar et al. [25], Oakland [12] and Sinclair and Zairi [15] also added the factor of continuous improvement for effective implementation. Finally, Dubrovski [26] and Kasul and Motwani [27] indicated that for a successful implementation of WCM, an integration of the entire company is required.

\subsection{Fiat Group Automobiles Production System, in the WCM Production System (FAPS)}

As defined by Massone [3], responsible for Production System Development of Fiat Group Automobiles Production System (FAPS), the introduction of FAPS concept is a great program of technological innovation that has the intention to change profoundly the way of producing, in order to achieve the standards of excellence set by the World Class Manufacturing (WCM).

For Professor Yamashina, cited by Massone [3], from the University of Kyoto, the basic and fundamental principle of WCM with FAPS is to bring the man to the entire production process to think and act effectively, and each time, act like men's of thought and think as men of action.

The model of Fiat Group Automobiles Production System (FAPS) is a structured set of methodologies and tools whose application spread across the enterprise through the involvement of all employees. It allows a radical improvement for the performance of the production system, optimizing all production processes and logistics working in continuous improvement of key factors: Quality, Productivity, Security, and Delivery. The implementation support is done by a system of Audits and it is structured by goals whose achievement is measured by performance indicators [3].
This allows the product to be delivered within the required time and quality, simultaneously eliminating activities that generates losses and do not add value (manpower, machinery, materials and energy).

The FAPS is constituted by 10 technical pillars of the WCM as described below [3]:

1) Safety - aims to eliminate accidents;

2) Cost Deployment-aims to identify problems that increase costs;

3) Focused Improvement-aims to develop the know how to reduce costs by using appropriate methods;

4) Autonomous Activities-consists in autonomous activity such as TPM (Autonomous Maintenance e Workplace Organization);

5) Professional Maintenance-it

6) Objectives zero breaking of machines;

7) Quality Control—SPC utilization (Statistical Process Control), Project Six Sigma, aiming at zero defect;

8) Logistics - utilization of logistics based on Picking foundations, just in time, Kan Ban, with the commitment to fully satisfy customers;

9) Early Equipament Management_Launch products providing adequate manufacturing. It utilizes fundamentals from QFD, FMEA of product and FMEA of process;

10) People Development-aims to create a culture of results by discipline and improving training of people in the organization;

11) Environment-It is the development of activities in a sustainable working environment for all in the organization, concerned with the prevention of environmental pollution.

The technical implementation of the 10 pillars of WCM in the production system of FAPS had as main objective to pursue a mental attitude or relevant philosophy to their scope and its improvement, following a well-defined path based on the removal of all barriers concerning production to achieve maximum simplification. There are many indications showing which obstacles should be eliminated in production and which routes should be followed for the simplification [3].

However, the production system of FAPS, which itself is based on WCM, becomes a formidable element of competitiveness for enterprises, and an important and lasting contributor to improving customer satisfaction.

\subsection{Describing the Cost Deployment}

Cost Deployment is a method that innovate systems management and control of establishments, introducing a strong link between individualization of the areas to be improved and the results of the performance improvements obtained through application of technical pillars of the WCM, measured through the appropriate KPI [3]. Consequently, it constitutes a reliable means to program 


\section{budgeting.}

Cost Deployment allows defining improvement programs that have an impact in reducing losses, everything that can be classified as wastes or non-value added in a systematic way. It also ensures collaboration between units of production and function of Administration and Control [2]. This is accomplished through:

1) The study of reactions between the cost factors, the processes that generate wastes and losses in its various kinds of ways;

2) The relationship between demand for waste reduction and losses, and reduction of related costs;

3) The verification of know-how to reduce waste and losses: if it is already available or it should be acquired;

4) Establishing a priority of projects to reduce waste and losses in accordance with the priorities derived from an analysis of costs/benefits;

5) The continuous monitoring of progress and results of improvement projects.

Cost Deployment is the ability to transform losses costs, quantifying in physical measurements: hours, $\mathrm{kW} / \mathrm{h}$, unit numbers of material, etc... [2].

The foundation of the methodology is the systematic identification of waste and losses of the area under examination, its evaluation and transformation into values. This is possible because it relates waste and losses to their causes and origins, allowing a complete definition of the loss.

In addition, Cost Deployment guides the individuali- zation of the best technical method to remove the cause and assess in detail the activity costs of removal and improving performance [2].

Figure 1 shows the detail of the logic route of Cost Deployment.

The completion of the logic route of Cost Deployment as shown in the figure is made up as follows:

1) From the establishment total costs of processing and from the analysis of its structure and composition, reduction targets and costs are established (step 1);

2) Losses and wastes are identified in a qualitative way, placing them in the processes in which they happen (The Matrix-Loss / Processes) (step 2);

3) It identifies the relationship between casual losses and all losses (Matrix B-Causal/Arising) (step 3);

4) The dimensions of losses and individualized wastes are transformed into costs, actual values (Matrix CCosts/Losses) (step 4);

5) Methodologies (WCM Pillars) are selected in order to remove the original causes of losses and wastes and as well as priorities are established (Matrix D—Losses/Methods) (step 5);

6) The costs of projects implementation are estimated expecting the removal of the causes and the benefits in terms of cost reductions (Matrix E-Costs/Benefits) (step $6)$;

7) Finally, improvement plans are implemented by collecting the results (step7) following them up.

As steps 1 to 4 consist of preparatory activities which
Process
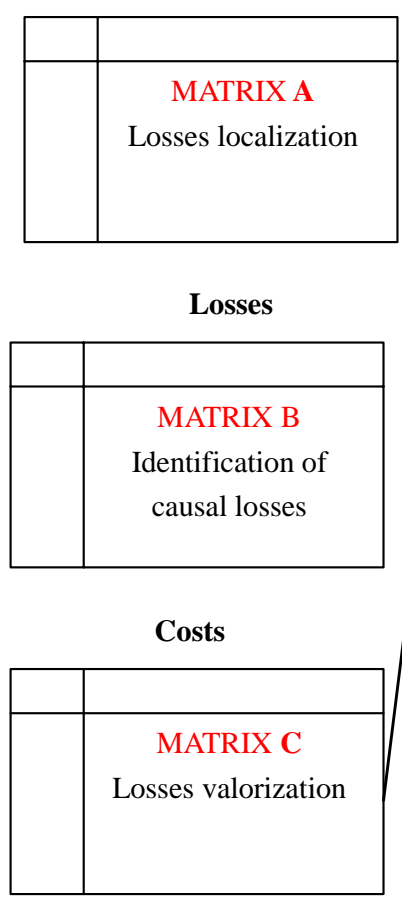

Methodology

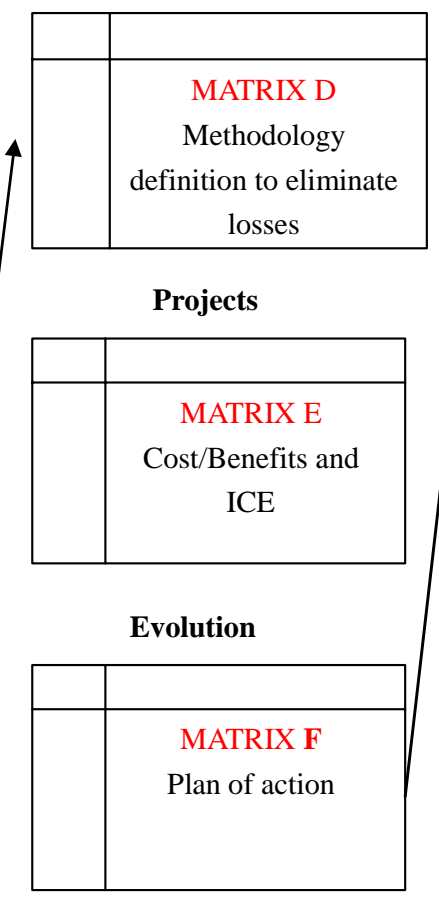

Budget

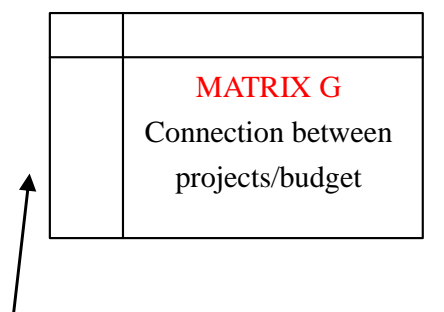

Figure 1. Logic route of cost deployment. 
serve to set priorities to make value-added activities of steps 5 to 7 really effective.

The first three steps are specifically designed to calculate and quantify the losses from the establishment budget data and establishment costs and from the operating data, as well.

The fourth and fifth steps aim to define the economy program, through the layering of economies in terms of costs and impacts for the improvement of relative KPIs. This stands as the definition of projects plan.

The sixth and seventh steps are intended to ensure the reporting and monitoring of results analyzing the quarterly progress of operating performance and the calculation of savings in costs and improvements.

After the completion of step 7, Cost Deployment activities should start at step 5, again taking into consideration the matrix A and the costs and losses, with the purpose of selecting other losses which had not been evidenced before because of resources lack, bad judgment, etc. This procedure permits these losses to be attacked with other projects then. In the case of lack of resources, they can be provided from previous projects.

Projects usually last three months. If projects are complex and require a longer time, it is important to divide them into subprojects with intermediate and shorter targets [2]. The following Figure 2 illustrates the seven steps of Cost Deployment methodology [2]:

The losses and wastes that occur during the execution of a production process are allocated to machines, people and materials.

Cost Deployment aims to determine the individualization of what is a loss and what is a waste, as well as its measurement, and the distinction between resulting cause and root cause.

In a production process which is characterized by generating an output from an input, the efficiency is the ability to produce an output (constant) and at least one input, so waste is defined as an excess input.

As the efficacy is given by the ability to produce a maximum output with a constant input, the loss is defined as unused input. In the imposing of Cost Deployment, first it's important to consider that in a production process 18 significant losses can be identified. They are grouped in terms of personnel and materials/energy [2].

Huge losses tied to machines operation are identified as losses that have impact on the overall efficiency of the equipment and as time losses, the time the equipment is off.

Regarding machines losses, Deployment Cost cannot always be seen immediately especially when a particular piece of equipment is critical in terms of effectiveness. By the way, it may be useful having Overall Equipment Effectiveness, OEE, as a reference. It lets to visualize equipment losses structure, taking into consideration technical efficiency, management and quality. OEE is an indicator that measures the overall rate of quality, the efficiency of delivery and the technical availability of the machine [2].

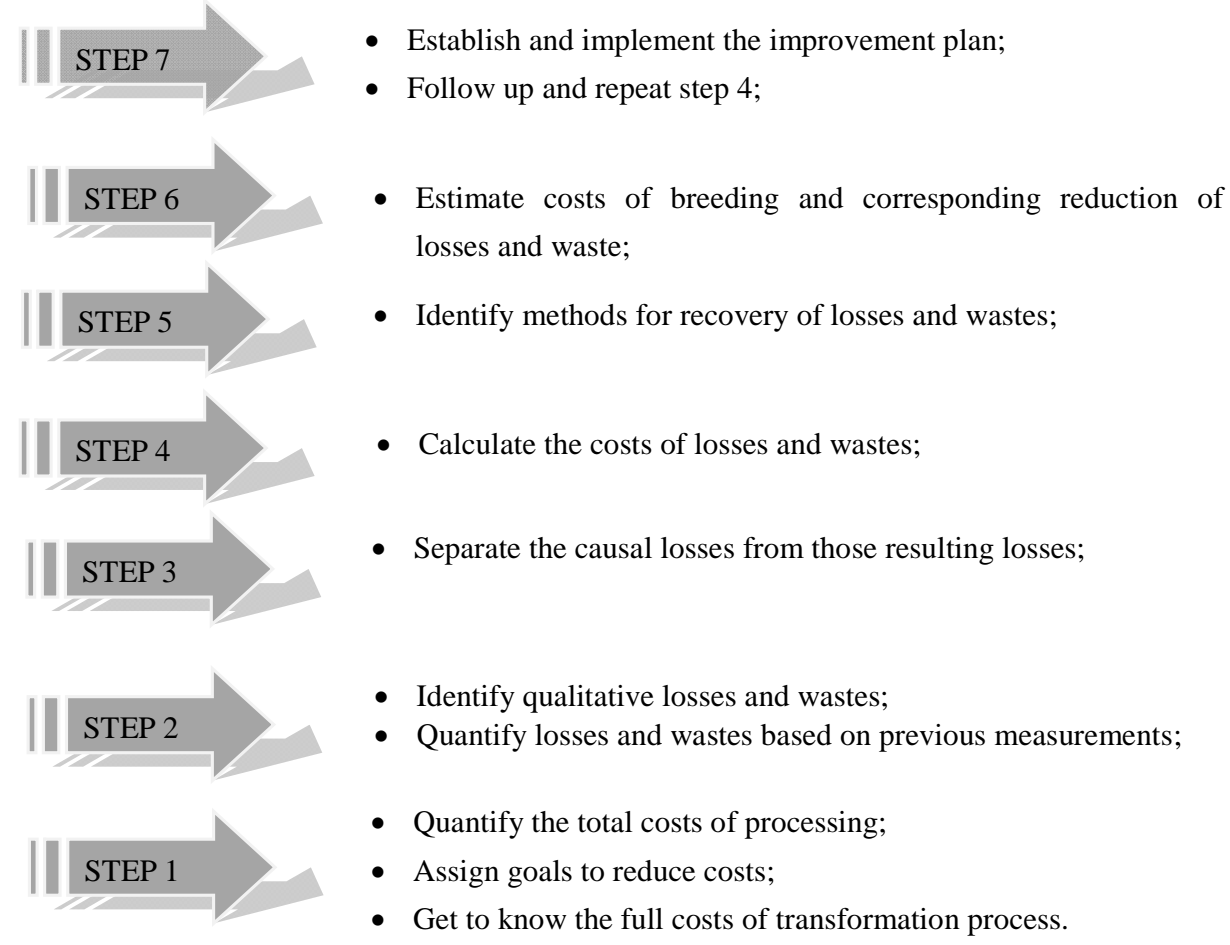

Figure 2. The seven steps of cost deployment. 
Yamashina [2] describes losses of operations related to equipment, people and material/energy. Losses tied to machines that hinder the overall efficiency of the equipment are:

1) Losses that interfere in the technical availability or timing of actual production;

2) Losses that hinder the efficiency of delivery: they are losses which interfere in the effective production time;

3) Losses that impair the quality level: they are losses that affect the effective time of production value;

4) Losses of equipment which have no impact on OEE: losses are attributable to loss of time and theoretical availability of equipment.

Losses caused by people can be grouped into five major losses:

1) Losses of management: waiting time for instructions or for materials, absences, strike, training and education programs;

2) Losses of operating movements: observation, walking, crouching, controlling;

3) Losses of line organization: desaturation, losses due to automation lack;

4) Losses committed by employees affecting quality: rework, lack of automatic control, measurement and implementation, human errors.

Material losses are grouped into three major losses:

1) Losses in the use of direct and consumable materials;

2) Losses in energy use;

3) Losses during maintenance.

Deployment Cost goes deeper. It considers not only resulting in losses as in the traditional way of managing the manufacturing, but also it tries to search for the cause of such losses. For example, loss of manpower can come from downtime that may have been originated from problems with components. These events may be originated in processes or sub-processes even though they were indirectly affected [2].

Therefore, the application of Cost Deployment in the technical pillars of Fiat Group Automobiles Production System allowed a strong acceleration of the results and the achievement of important advantages in reducing losses. This method is the compass that directs and guides continuous improvement projects [3].

\section{Conclusions}

Industries are not unrelated to the changes that are occurring in the current competitive scenario. However, some management leaders who are part of the same scenario have not given proper treatment for issues related to the specificities of each organization [28].

The philosophy of World Class Manufacturing (WCM) has proven to be sophisticated and efficient in order to operate in highly globalized and competitive markets, and that their current innovation process, Cost Deployment, radicalized the optimization of production costs and logistic processes.

By analyzing Cost Deployment methodology, it was possible to understand that it also allows linking operational performances which are usually measured with indicators such as efficiency, providing numbers of defect, hours of desaturation, etc... Normally, these indicators are non-comparable among them or with economic performance. They are valued at cost providing a common language to institutions allowing effective definition of the priorities for improvement.

Cost Deployment methodology also enables focus on areas where the greatest casual losses are placed providing opportunities for greater efficiency and effectiveness in reducing and eliminating them. It also facilitates the selection of methodologies and technical pillars to be activated in order to remove or correct the causes of such losses, allowing an easy evaluation of costs and benefits [2].

To face this new challenge of implementing Cost Deployment in operating activities of WCM, Fiat Group Automobiles Production System (FAPS) must be always innovating and successively acquiring new organizational knowledge in order to always present a competitive posture. Therefore, it is necessary to create a proper environment to create and implement innovative, flexible and non-rigid structures operational processes.

\section{REFERENCES}

[1] H. Yamashina, "Just-in-Time Production-A New Formulation and Algorithm of the Flow Shop Problem," Computer-Aided Production Management, Vol. 34 No. 3, 1998, pp. 120-140.

[2] H. Yamashina, "Manufacturing Cost Deployment,” Journal of the Japan Society for Precision Engineering, Vol. 65, No. 2, 1999, pp. 260-266. doi:10.2493/jispe.65.260

[3] L. Massone, "Fiat Group Automobiles Production System: Manual do WCM, Wold Class Manufacturing: Towards Excellence Class Safety, Quality, Productivity and Delivery,” Ed. Fiat, Brazil, 2007.

[4] R. J. Schonberger, "The Vital Elements of World-Class Manufacturing,” International Management, Vol. 41, No. 5, 1986, pp. 76-78.

[5] A. Caron, "Technological Innovations in Small and Medium Industrial Enterprises in Times of Globalization: The Case of Paraná,” Thesis (Doctoral in Production Engineering), Curitiba, 2003.

[6] H. Chesbrougr, "Technological Innovation Requires Enterprise Networking,” 2011. http://www.inovacaotecnologica.com.br/noticias/noticia.p hp?artigo=inovacao-tecnologica-pressupoe-networking-e mpresarial 
[7] R. H. Hayes and S. C. Wheelwright, "Restoring Our Competitive Edge: Competing Through Manufacturing," Wiley, New York, 1984.

[8] D. Buchanan and A. Huczynski, "Organizational Behavior,” 5th Edition, Prentice-Hall, Harlow, 2004.

[9] A. Escrig-Tena, "TQM as a Competitive Factor: A Theoretical and Empirical Analysis,” International Journal of Quality \& Reliability Management, Vol. 21 No. 6, 2004, pp. 612-637. doi:10.1108/02656710410542034

[10] B. B. Flynn, R. G. Schoroeder and E. G. Flynn, "World Class Manufacturing: An Investigation of Hayes and Wheelwright's Foundation," Journal of Operation Management, Vol. 17, No. 3, 1999, pp. 249-269. doi:10.1016/S0272-6963(98)00050-3

[11] R. Mcadam and J. Henderson, "Influencing the Future of TQM: Internal and External Driving Factors,” International Journal of Quality \& Reliability Management, Vol. 21, No. 1, 2004, pp. 51-71. doi:10.1108/02656710410511696

[12] J. S. Oakland, “Total Organizational Excellence: Achieving World Class Performance,” Elsevier, Oxford, 2001.

[13] I. S. Salaheldin and R. Eid, "The Implementation of World Class Manufacturing Techniques in Egyptian Manufacturing Firms: An Empirical Study,” Journal of Industrial Management \& Data Systems, Vol. 107, No. 4, 2007, pp. 551-566. doi:10.1108/02635570710740698

[14] M. Sharma and R. Kodali, "Development of a Framework for Manufacturing Excellence,” Measuring Business Excellence, Vol. 12, No. 4, 2008, pp. 55-60. doi:10.1108/13683040810919962

[15] D. Sinclair and M. Zairi, “An Empirical Study of Key Elements of Total Quality Based Measurement Systems: A Case Study Approach in the Service Industry Sector,” Total Quality Management, Vol. 12, No. 4, 2001, pp. 535550. doi:10.1080/09544120120066127

[16] A. S. Sohal and M. Terziovski, "TQM in Australian Manufacturing: Factors Critical to Success,” International Journal of Quality \& Reliability Management, Vol. 17, No. 2, 2000, pp. 158-168. doi:10.1108/02656710010304564

[17] M. Svensson and B. Klefsjo, "Experiences from Creating a Quality Culture for Continuous Improvements in Swedish School Sector by Using Self-Assessments," Total Quality Management, Vol. 11, No. 4-6, 2000, pp. 800807. doi:10.1080/09544120050008246

[18] T. Butler and B. Fitzgerald, "Unpacking the Systems Development Process: An Empirical Application of the CSF
Concept in a Research Context," The Journal of Strategic Information Systems, Vol. 8, No. 4, 1999, pp. 351-371. doi:10.1016/S0963-8687(00)00027-5

[19] A. L. Digman, "Strategic Management: Concepts, Decisions, Cases," 2nd Edition, Irwin, Homewood, 1990.

[20] R. Eid, I. Elbeltagi and M. Zairi, "Making B2B International Internet Marketing Effective: A Study of Critical Factors Using a Case-Study Approach,” Journal of International Marketing, Vol. 14, No. 4, 2006, pp. 87-109. doi:10.1509/jimk.14.4.87

[21] J. S. Oakland, “Total Quality Management-Text with Cases,” Butterworth-Heinemann, Oxford, 1995.

[22] G. J. Avlonitis and A. D. Karayanni, “The Impact of Internet Use on Business-to-Business Marketing: Examples from American and European Companies," Industrial Marketing Management, Vol. 29, No. 5, 2000, pp. 441-459. doi:10.1016/S0019-8501(99)00071-1

[23] C. A. Mora-Monge, M. E. Gonz'lez, G. Quesada and S. S. Rao, "A Study of AMT in North America: A Comparison between Developed and Developing Countries,” Journal of Manufacturing Technology Management, Vol. 19, No. 7, 2008, pp. 812-829. doi:10.1108/17410380810898769

[24] R. Bose, "Customer Relationship Management: Key Components for IT Success," Industrial Management \& Data Systems, Vol. 102, No. 2, 2002, pp. 89-97. doi:10.1108/02635570210419636

[25] G. S. Sureshchandar, C. Rajendran and R. N. Anantharaman, "A Conceptual Model for Total Quality Management in Service Organizations,” Total Quality Management, Vol. 12, No. 3, 2001, pp. 343-363. doi:10.1080/09544120120034492

[26] D. Dubrovski, "The Role of Customer Satisfaction in Achieving Business Excellence,” Total Quality Management, Vol. 12, No. 7, 2001, pp. 920-925. doi:10.1080/09544120100000016

[27] R. Kasul and J. Motwani, "Performance Measurement in World-Class Operations,” Benchmarking for Quality Management \& Technology, Vol. 2, No. 2, 1995, pp. 20-36. doi:10.1108/14635779510090508

[28] L. C. S. Silva, J. L. Kovaleski, S. Gaia, E. A. S. A. de Matos and A. C. de Francisco, "The Challenges Faced by Brazil's Public Universities as a Result of Knowledge Transfer Barriers in Building the Technological Innovation Center," African Journal of Business Management, Vol. 6, No. 41, 2012, pp. 10547-10557. doi:10.5897/AJBM12.315 